\title{
The Introduction of Local Culture as a Means of Learning Indonesian Language for Foreign Speakers
}

\author{
Estuning Dewi Hapsari ${ }^{1}$ \\ ${ }^{1}$ University Of PGRI Madiun, Indonesia, \\ 1estuning@unipma.ac.id
}

\begin{abstract}
The teaching of Bahasa Indonesia to foreign speakers (BIPA) cannot be separated by local cultures. This condition is supported by the BIPA curriculum that includes the local culture. However, Indonesian language teaching for foreign speakers cannot be confused with Indonesian language instruction in native Indonesian students. This is due to differences in mother tongue and cultural background. This research is a qualitative descriptive study. Data collection is done through observation, recording, and documentation. The validity technique uses source triangulation to check the validity of the data. Based on the results of the research known that the local culture of Madiun, such as Dongkrek, Reog Ponorogo, Madiun tourism, and special food can be used as a means of Indonesian language recognition. Through the introduction of local cultures makes foreign learners easy to understand Indonesian vocabulary. Thus listening and speaking skills are easier to apply.
\end{abstract}

Keywords: Local culture, media, Madiun, Dongkrek, Madiun Tour

\section{PENDAHULUAN}

Proses pengajaran bahasa Indonesia tidak dapat dipisahkan dengan pengenalan budaya. Hal tersebut dikarenakan bahasa merupakan cerminan budaya suatu bangsa. Bahasa merupakan hasil budaya masyarakat yang cukup kompleks dan senantiasa berkembang aktif. Kompleksitas bahasa dikarenakan unsur-unsur bahasa yang tersimpan mengandung banyak pemikiran dari berbagai hal yang dimiliki oleh suatu masyarakat. Bahasa juga senantiasa aktif mengikuti perkembangan ilmu pengetahuan dan teknologi. Budaya merupakan bagian dari perkembangan yang berada pada akal dan beberapa kemungkinan serta tenaga alam yang memungkinkan tenaga manusia sehingga menghasilkan sesuatu yang seimbang [1]. Sesuai dengan tujuan awal, internasionalisasi bahasa Indonesia menjadikan bahasa Indonesia sebagai sarana menyampaikan pesan yang isinya berupa nilai-nilai luhur bangsa. Upaya pengenalan nilai luhur bangsa tidak dapat lepas dengan kondisi budaya.

Bahasa adalah bagian dari kebudayaan [2]. Berdasarkan pendapat tersebut, dapat dibuktikan ketika kita mempelajari suatu bahasa. Melalui bahasa, secara tidak langsung kita akan mempelajari budaya asal bahasa. Maka dari itu, penyusunan kurikulum BIPA mencantumkan beberapa budaya Indonesia diantaranya cerita rakyat, keberagaman pariwisata, dan mengenal tempat bersejarah di Indonesia. 
Berbagai potensi budaya yang telah dimiliki membuat para pengajar bahasa Indonesia lebih mengembangkan proses pengajaran secara variatif untuk mengmbangkan eksistensi bahasa Indonesia. Proses aktualisasi bahasa Indonesia dilakukan dengan mengenalkan beberapa kebudayaan lokal yang menjadi identitas atau ciri setiap wilayah di seluruh penjuru tanah air. Kebudayaan lokal dijadikan sebagai media komunikasi bagi penutur asing. Kebudayaan lokal dikenalkan melalui teks bacaan dan melihat langsung pentas budaya atau atraksi budaya.

Budaya lokal merupakan pandangan hidup dari suatu komunitas yang telah berkembang baik secara sosial ataupun etnik dengan batasan letak daerah, unsur geografis, serta pengalaman sejarah [3]. Budaya lokal dapat berupa seni, tradisi, hukum adat, serta pola pikir suatu masyarakat. Budaya lokal di setiap daerah memiliki ciri dan keunikan yang menggambarkan kekayaan di daerah tertentu. Pengenalan budaya lokal dapat dijadikan sebagai media mengenalkan bahasa Indonesia bagi penutur asing. Cara memperkenalkan budaya lokal dapat dilakukan dengan menginternalisasi budaya dengan materi pengajaran BIPA. Budaya dipilih karena terdapat keterkaitan antara budaya dan bahasa. Cara menentukan identitas suatu budaya bergantung pada 'bahasa' (bahasa merupakan unsur kebudayaan yang bersifat nonmaterial) bagaimana merepresentasikan sebuah bahasa akan dijelaskan melalui identitas serta kenyataan yang akan dirinci kemudian dibandingkan [4] . Dengan mengangkat budaya lokal, akan tercapai dua hal sekaligus yaitu materi yang disampaikan dan pengenalan budaya lokal.

Budaya lokal mengandung unsur-unsur kerohanian yang di dalamnya menggerakkan martabat dan nilai dalam diri manusia dan menjadikan manusia lebih sempurna. Pengenalan budaya Indonesia termasuk budaya lokal sesuai dengan tercantum dalam kurikulum BIPA. Melalui pengenalan budaya lokal, diharapkan akan meningkatkan tingkat pemahaman dan daya ingat pemelajar asing dalam belajar bahasa Indonesia. Budaya lokal memiliki kaitan dengan pola kehidupan masyarakat di sutau tempat. Masyarakat yang saling menjalin hubungan antara dirinya dengan orang lain, dengan Tuhan, yang berlangsung secara harmonis. Hubungan yang dijalin memiliki tujuan menjaga kelangsungan hidup dalam suatu komunitas. Kelangsungan hidup yang dijaga akan memberi corak kehidupan, yaitu menciptakan kearifan lokal. Kearifan lokal berkaitan dengan komunitas tradisional yang hidup di suatu tempat [5]. Kearifan lokal mengandung nilai-nilai lokal yang ditaati oleh semua anggota.

Bahasa Indonesia bagi penutur asing merupakan kegiatan yang mulai dirintis di Universitas PGRI Madiun (UNIPMA) sejak menjalin kerja sama dengan beberapa universitas asing. Universitas yang telah menjalin kerja sama mengirimkan mahasiswa ke UNIPMA untuk magang selama beberapa bulan. Pembelajaran bahasa Indonesia dikenalkan untuk memudahkan komunikasi mahasiswa asing yang berada di tempat magang. Pengenalan bahasa Indonesia tidak terlepas dari penyajian budaya lokal yang ada.

Mengenalkan bahasa Indonesia bagi mahasiswa asing berbeda dengan pengajaran bahasa Indonesia pada umumnya. Unsur pembeda yang terlihat jelas adalah mahasiswa asing yang datang ke Madiun telah memiliki bahasa pertama (b1) dengan latar belakang budaya yang tentunya berbeda. Pelajar BIPA adalah pelajar kewarganegaraan asing dengan perbedaan latar budaya melalui budaya bahasa yang telah dipelajari sebelumnya [6]. Berdasarkan permasalahan tersebut, maka diperlukan pendekatan ketika mengenalkan bahasa Indonesia bagi mahasiswa asing harus menggunakan metode, teknik, dan media yang sesuai dengan usia dan tujuan mahasiswa asing belajar ke Indonesia [7]. Maka dari itu, budaya lokal dapat menjadi salah satu sarana atau media pengenalan bahasa Indonesia.

Penelitian terkait pengenalan budaya lokal bagi penutur asing pernah dilakukan oleh R. Panji Hermoyo dan Suher. Judul penelitian yang diambil adalah Peranan Budaya Lokal Dalam Materi Ajar Bahasa Indonesia Bagi Penutur Asing (BIPA) tahun 2017. Berdasarkan hasil penelitian diperoleh hasil bahwa budaya lokal Jawa Timur dapat menjadi referensi dalam mengenalkan 
bahasa sekaligus budaya Indonesia kepada mahasiswa asing. Melalui pengenalan budaya lokal, memudahkan pengajar mengenalkan bahasa Indonesia kepada mahasiswa asing.

\section{METODE PENELITIAN}

Penelitian ini merupakan penelitian kualitatif. Metode yang digunakan adalah deskriptif kualitatif. Penelitian kualitatif menurut R. Panji Hermoyo merupakan penelitian yang memiliki tujuan untuk memahami fenomena yang dialami oleh subjek penelitian [8]. Fenomena dapat berupa perilaku, persepsi, tindakan, motivasi, dan lain sebagainya yang secara keseluruhan dan deskriptif berupa kata-kata dan bahasa pada kondisi khusus alamiah dengan memanfaatkan metode alamiah yang sesuai. Penelitian kualitatif melibatkan peneliti untuk memahami fenomena yang ada dan menjadi hal penting untuk dianalisis dan dideskripsikan melalui bahasa tulis. Peneliti harus mampu memaparkan kejadian yang terjadi secara objektif.

Pengumpulan data merupakan cara strategis dalam sebuah penelitian. Tujuan pengumpulan data adalah untuk mendapatkan data. Peneliti harus melakukan berbagai cara guna mendapatkan data yang valid. Maka dari itu, pengumpulan data dilakukan dengan observasi, pencatatan, dan dokumentasi. Teknik validasi data yang dipilih adalah teknik triangulasi. Pada penelitian ini digunakan triangulasi sumber. Triangulasi sumber akan mengecek kembali tingkat kepercayaan sebuah informasi dari sumber data. Dengan demikian hasil penelitian yang diperoleh akan ditinjau dan disesuaikan dengan teori yang sesuai berdasarkan data yang diperoleh di lapangan.

\section{HASIL DAN PEMBAHASAN}

Student Teacher Exchange in Southeast Asia (SEA-Teacher Project) merupakan salah satu program pertukaran pelajar dari Southeast Asia Ministers of Education Organization (SEAMEO). Melalui program SEA-Teacher mahasiswa akan magang selama satu bulan di tempat yang sesuai dengan jurusan masing-masing. Mahasiswa akan ditempatkan di sekolah atau industri yang telah memiliki kerja sama dengan kampus. Bagi mahasiswa jurusan pendidikan, salah satu tugas yang diemban adalah melakukan revitalisasi pendidikan, terutama meningkatkan kapabilitas guru dalam mengajar.

Terdapat beberapa materi yang diberikan bagi mahasiswa magang. Salah satu materi wajib yang didapatkan yaitu materi bahasa Indonesia. Materi tersebut diberikan untuk memudahkan proses komunikasi. Melalui penguasaan bahasa Indonesia, proses magang di tempat-tempat yang telah dipilih dapat berjalan dengan lancar. Hal tersebut dikarenakan mahasiswa asing mudah berkomunikasi dengan orang-orang yang terlibat selama magang Dengan demikian semua maksud dan tujuan magang dapat tercapai.

Pemberian materi bahasa Indonesia bagi penutur asing bertujuan untuk membuat pembelajar asing mampu berbahasa Indonesia secara wajar [9]. Maksud dari wajar adalah mampu berbahasa Indonesia layaknya orang Indonesia. Maka dari itu, pengenalan budaya menjadi bagian yang cukup penting. Selain itu, untuk mengenalkan bahasa Indonesia perlu dukungan berupa sikap positif dari penutur asli [10]

Pengenalan bahasa Indonesia tidak dapat dipisahkan dengan budaya pada saat kelas bahasa Indonesia berlangsung. Pemahaman budaya lokal dari penutur asli akan membantu proses pembelajaran bahasa Indonesia. Budaya lokal merupakan semua aktivitas yang dilakukan oleh suatu masyarakat untuk mengatasi masalah dan memenuhi kebutuhan hidup [11]. Mereka dikenalkan dengan budaya dan makanan lokal yang ada di Madiun. Pengenalan budaya lokal bertujuan untuk memperkenalkan budaya lokal kepada mahasiswa asing sekaligus sebagai sumber informasi pengetahuan agar mahasiswa asing lebih dekat dengan budaya lokal dimana 
dia berada. Melalui pengenalan budaya lokal, materi lebih mudah diterima. Dengan demikian budaya lokal menjadi media dalam mengenalkan bahasa Indonesia bagi penutur asing.

Semua benda budaya yang dapat menjadi media pembelajaran BIPA dikatakan sebagai media pembelajaran [12]. Media yang digunakan antara lain pengenalan seni dongkrek dan reog Ponorogo. Mahasiswa asing begitu antusias dengan pagelaran dongkrek dan reog yang didalamnya terdapat unsur mistis dan religius. Pesan yang ada di dalam pagelaran seni tersebut membuat mereka begitu kagum bahwa orang Madiun merupakan orang yang tidak menyerah dalam mempertahankan hidup. Melalui budaya, kompetensi untuk mendapatkan informasi wisata dan sejarah telah terpenuhi. Dengan demikian, media merupakan salah satu alat untuk mencapai tujuan pembelajaran [13].

Memahami karakteristik pelajar asing juga menjadi salah satu cara untuk menentukan dan mengembangkan materi BIPA. Dalam pembelajaran BIPA materi yang diajarkan antara lain ragam suku di Indonesia, kebiasaan masyarakat Indonesia, tradisi Indonesia, tempat-tempat bersejarah, gotong-royong, tata krama (sopan santun) dan lain sebagainya. Konteks permasalah yang luas tersebut dibatasi pada budaya lokal di Madiun karena mereka berada di Madiun. Pengenalan budaya didukung melalui praktik dan pengamatan langsung ketika mahasiswa berada di lapangan.

Pada proses pembelajaran mengungkapkan harapan, doa, dan ucapan selamat. Mahasiswa dibawa untuk melihat kesenian dongkrek. Dongkrek merupakan kesenian asli daerah Madiun. Cerita singkat di dalam dongkek disampaikan kepada mahasiswa pada saat melihat atraksi dongkrek. Selain itu, cerita dongkrek yang telah dilihat secara langsung juga dituangkan dalam naskah cerita. Di dalam naskah cerita terdapat beberapa kosakata yang harus dipahami. Kosakata yang telah diketahui artinya, kemudian mahasiswa asing mengungkapkan kembali menjadi kalimat. Melalui pengamatan langsung kesenian dongkrek, mereka mudah untuk menyampaikan kalimat ucapan selamat, doa, dan harapan. Selain itu, juga memudahkan mahasiswa menceritakan kembali sejarah dan pesan yang di dalam kesenian dongkrek.

Mahasiswa asing juga diberikan kesempatan menikmati jenis masakan asli Madiun, seperti pecel, madumongso, brem, lempeng serta berwisata di beberapa daerah Madiun. Ketika berwisata di beberapa daerah Madiun, seperti Telaga Sarangan, mereka cukup kagum melihat sopan santun pedagang pada waktu menjajakan dagangannya dengan menggunakan bahasa Jawa. Pengalaman yang didapatkan melalui budaya, makanan, dan tempat wisata, dijadikan sebagai model dan contoh dalam mempelajari bahasa Indonesia. Ketika mereka belajar kosa kata bahasa Indonesia, kosakata akan mudah dihafal menggunakan contoh yang pernah mereka dengar dan lihat.

Budaya lokal memiliki peran bahwa budaya Indonesia sangat beragam. Mahasiswa asing yang melihat dan mengamati secara langsung akan mengetahui ciri khas budaya tersebut. Ketika mahasiswa asing tertarik dengan budaya lokal dan ingin mempelajarinya, secara tidak langsung mereka akan belajar bahasa Indonesia. Kondisi tersebut didukung oleh pendapat Rahyono yang menyatakan mempelajari budaya lokal memiliki beberapa nilai strategis, diantaranya (1) budaya lokal adalah sebuah identitas, (2) kearifan lokal tidak asing bagi pemiliknya, (3) pengaruh emosi dalam budaya lokal cukup kuat, (4) kearifan lokal akan menumbuhkan harga diri seseorang, (5) kearifan lokal mampu meningkatkan harkat dan martabat bangsa [14] [15].

\section{SIMPULAN}

Pembelajaran BIPA merupakan salah satu cara pengenalan bahasa Indonesia di mata internasional. Pengenalan bahasa Indonesia tidak dapat dilepaskan dengan pengenalan budaya lokal. Melalui pengenalan budaya lokal masyarakat internasional akan mengenal kondisi bangsa 
Indonesia. Budaya lokal dapat dijadikan sebagai sarana atau media menyampaikan kosakata bahasa Indonesia kepada mahasiswa asing. Budaya lokal juga mampu menjadi sarana pendidikan karakter masyarakat Indonesia. Maka dari itu, pengenalan budaya lokal harus dilakukan untuk mencegah munculnya krisis moral generasi muda akibat kegagalan dari pendidikan budaya. Pengenalan budaya lokal akan memudahkan mahasiswa asing memahami maksud kosakata yang dipelajari. Dengan demikian, penguasaan bahasa akan meningkat. Diperlukan keterampilan penguasaan budaya bagi pengajar asing agar mampu mentransfer bahasa Indonesia kepada pebelajar asing.

\section{REFERENCES}

[1] Z. Zoetmulder, Kalagwan a survey of old Javanese literature. California: Martinus Nijhoff, 1974.

[2] K. Koentjaraningrat, Pengantar Ilmu Antropologi. Yogyakarta: Aksara Baru, 1985.

[3] N. A. Fauzie, Budaya Muakhi Dan Pembangunan Daerah Menuju Masyarakat Bermartabat. Yogyakarta, 2009.

[4] R. Suprapti, "Implementasi Pendidikan Multikultural di SD Negeri Paliyan I Gunung Kidul," Universitas Islam Indonesia, 2013.

[5] S. Sudikan, Kearifan Budaya Lokal. Yogyakarta: Damar Ilmu, 2013.

[6] I. Suyitno, "Norma Pedagogis dan Analisis Kebutuhan Belajar dalam Pembelajaran Bahasa Indonesia untuk Penutur Asing (BIPA)," Diksi, vol. 15, no. 1, 2008.

[7] L. Muliastuti, "BIPA Pendukung Internasionalisasi Bahasa Indonesia," untidar, 2006.

[8] R. P. Hermoyo, "Peranan budaya lokal dalam materi ajar bahasa indonesia bagi penutur asing (bipa)," vol. 1, no. 1916, pp. 120-126, 2017.

[9] S. Suher and P. Hermoyo, "Pengembangan Materi Ajar BIPA Melalui Budaya Lokal Jawa Timur," ELSE (Elementary Sch. Educ. Journal) J. Pendidik. dan Pembelajaran Sekol. Dasar, vol. 1, no. 1, 2017.

[10] M. P. Handoko, R. N. Fahmi, F. Y. Kurniawan, H. Artating, and S. Meili, "Potensi pengembangan bahasa Indonesia menjadi bahasa internasional," vol. 1, no. 1, pp. 2229, 2019.

[11] H. Suteja and C. Purwanti, "Code Switching in BIPA Classes: Teachers' and Students' Attitudes,” Polyglot J. Ilm., vol. 13, no. 1, pp. 43-52, 2017.

[12] A.Kusmiatun, Mengenal BIPA dan Pembelajarannya. Yogyakarta: K Media, 2016.

[13] P. V. Asteria and D. N. Farida, "E-Mikuta (Komik Saku Kosakata Elektronik): Media Pembelajaran BIPA Berbasis Teknologi," in Kongres Bahasa Indonesia, 2018.

[14] U. Fajarini, "Peranan kearifan lokal dalam pendidikan karakter," SOSIO-DIDAKTIKA Soc. Sci. Educ. J., vol. 1, no. 2, pp. 123-130, 2014.

[15] K. Saddhono, "Integrating culture in Indonesian language learning for foreign speakers at Indonesian universities,” J. Lang. Lit., vol. 6, no. 2, 2015. 